\title{
The effects of killer cell immunoglobulin-like receptor (KIR) genes on susceptibility to HIV-1 infection in the Polish population
}

\author{
Katarzyna Zwolińska $^{1}$ • Olga Blachowicz ${ }^{1}$ - Tomasz Tomczyk ${ }^{1}$ - Brygida Knysz ${ }^{2}$. \\ Jacek Gąsiorowski $^{2}$ - Małgorzata Zalewska ${ }^{2}$ - Beata U. Orzechowska ${ }^{1}$. \\ Marta Sochocka $^{1} \cdot$ Egbert Piasecki $^{1}$
}

Received: 6 October 2015 / Accepted: 1 February 2016 /Published online: 18 February 2016

(C) The Author(s) 2016. This article is published with open access at Springerlink.com

\begin{abstract}
Killer cell immunoglobulin-like receptors (KIR) are the most polymorphic receptors of natural killer (NK) cells. Their activity diversifies the functions of NK cells in the antiviral immune response, so the presence of certain KIR may affect transmission of HIV-1. The aim of the study was to evaluate the influence of KIR genes on the susceptibility to HIV-1 infection in the Polish population depending on the route of exposure. We determined the frequencies of activating $(2 D S 1,2 D S 2$, $2 D S 3,2 D S 4 f, 2 D S 4 d e l, 2 D S 5,3 D S 1)$ and inhibitory (2DL1, 2DL2, 2DL3, 2DL5, 3DL1) KIRs in HIV-1-positive patients $(n=459)$, individuals exposed to HIV-1 but uninfected (EU, $n=118$ ) and in uninfected, healthy blood donors (BD, $n=98$ ). Analysis was performed using stepwise logistic regression. Apart from KIRs, CCR5- $\triangle 32$, and CCR2-64I, alleles were also analyzed, as we knew or suspected that these features could affect susceptibility to HIV infection. The regression confirmed the protective effect of $C C R 5-\triangle 32(\mathrm{OR}=0.25, p=0.006)$ and CCR2-64I ( $\mathrm{OR}=0.59, p=0.032)$ against HIV infection. Among KIR genes, $2 D L 3$ was found to be a protective factor $(\mathrm{OR}=0.30, p=0.015)$. A similar effect was seen for $3 D S 1$ but only in intravenous drug users (IDUs) $(\mathrm{OR}=0.30, p=0.019)$, not in sexually exposed people. $2 D L 5$ was found to be a factor facilitating HIV infection $(\mathrm{OR}=2.13, p=0.013)$. A similar effect was observed for $2 D L 2$ but only in females $(\mathrm{OR}=2.15$,
\end{abstract}

Katarzyna Zwolińska

kjzwolinska@iitd.pan.wroc.pl

1 Laboratory of Virology, Ludwik Hirszfeld Institute of Immunology and Experimental Therapy, Polish Academy of Sciences, Weigla 12, 53-114 Wroclaw, Poland

2 Department of Infectious Diseases, Liver Diseases and Acquired Immune Deficiencies, Wroclaw Medical University,

Wroclaw, Poland $p=0.040)$, and $2 D S 1$ in IDUs $(\mathrm{OR}=3.03, p=0.022)$. Our results suggest a beneficial role of KIR3DSI and $2 D L 3$ supporting resistance to HIV infection and a harmful effect of $2 D S 1,2 D L 5$, and $2 D L 2$ genes promoting HIV acquisition.

Keywords Susceptibility to HIV infection · Killer cell immunoglobulin-like receptors (KIR) · Chemokine receptors · Host genetics

\section{Introduction}

The importance of host genetic factors in HIV infection has been known for the last 20 years, from the role of the mutations in genes encoding chemokines and their receptors, to specific microRNA interfering with the virus replication cycle (Arenzana-Seisdedos and Parmentier 2006; Farberov et al. 2015; Lama and Planelles 2007; O'Brien and Moore 2000; Reynoso et al. 2014; Zwolińska 2009). The nature and mode of action of these factors are very diverse. It includes the prevention of HIV entry into the cells, as it is observed for CCR5- 432 mutation (O’Brien and Moore 2000; Zwolińska et al. 2013a), the modulation of the immune response against virus, as it is shown in case of HLA and killer cell immunoglobulin-like receptors (KIR) (Jennes et al. 2006, 2013; Martin et al. 2002), and finally the specific epigenetic mechanisms of microRNA (Farberov et al. 2015; Reynoso et al. 2014). The role of genetic features in HIV infection is not always clear, and sometimes the results of research are ambiguous or contradictory. This applies to the mutation in chemokine receptors used as HIV co-receptors, e.g., CCR264I (Ding et al. 2011; Zapata et al. 2013), human endogenous retroviruses (Bhardwaj et al. 2014; van der Kuyl 2012; Zwolińska 2006; Zwolińska et al. 2013b), and genes encoding KIR, especially in the context of susceptibility to the virus 
(Hong et al. 2013; Paximadis et al. 2011; Tallon et al. 2014; Tiemessen et al. 2011).

KIR are very polymorphic structures on natural killer (NK) cells which are able to trigger their function due to passing activating or inhibitory signals. Such regulation affects both innate and adaptive immunity, particularly the antiviral response. To date, 16 KIR genes, 601 alleles, more than 50 haplotypes, and 398 KIR genotypes have been identified (González-Galarza et al. 2015; Takeshita et al. 2013). Among them, there are seven genes encoding receptors transmitting activating signals through the short cytoplasmic tail (KIR2DS1, 2DS2, 2DS3, 2DS4, 2DS5A, 2DS5B, and 3DS1), and eight genes encoding inhibitory receptors with long cytoplasmic tails (KIR2DL1, 2DL2, 2DL3, 2DL5A, 2DL5B, 3DL1, $3 D L 2$, and $3 D L 3)$. KIR2DL4 may activate or inhibit NK cell activity (Faure and Long 2002; González-Galarza et al. 2015). Framework genes KIR $3 D L 3,2 D L 4$, and $3 D L 2$ and pseudogene $3 D P 1$ are present in almost all human genomes, with rare exceptions (Niepiekło-Miniewska et al. 2014). KIR genes are located in 15 different loci on chromosome 19q13.4, and some of them are allelic variants, KIR3DL1/S1, 2DL2/ 2DL3, and 2DS3/2DS5 (Jiang et al. 2012; Martin and Carrington 2013). KIR haplotypes can possess from 7 to 12 genes and may be divided into two main haplotype groups $\mathrm{A}$ and $\mathrm{B}$ on the basis of the presence of specific genes in centromeric and telomeric regions of the cluster. Centromeric A (cenA) haplotype is characterized by the presence of KIR2DL3 and the absence of $2 D L 2$ and $2 D S 2$. The last two are determinants of centromeric B (cenB) haplotype. Telomeric A (telA) haplotype is defined by the presence of $3 D L 1$ and $2 D S 4$ (both, full length or form with 22-bp deletion, 2DS4del) and the absence of 2DS1. 2DS1 and 3DS1 are typified of telomeric B (telB) haplotype, where there is neither 2DS4 nor 3DL1 (Jiang et al. 2012). Some KIR alleles of one gene may occupy different loci in centromeric or telomeric regions (e.g., 2DS3/2DS5, 2DL5) (Jiang et al. 2012). Haplotype A (cenA/telA) usually contains framework genes plus KIR2DL1, 2DL3, 2DS4, and 3DL1 (Martin et al. 2000, 2004; Takeshita et al. 2013), and therefore activating signal transmission by the KIR is limited, especially when KIR2DS4 has a 22-bp deletion (2DS4del) (Graef et al. 2009). Haplotype $\mathrm{B}(\operatorname{cen} \mathrm{A} / \mathrm{telB}$; cenB/telA; cenB/telB) is more variable and has more combinations of activating KIR $(2 D S 1,2 D S 2,2 D S 3$, 2DS5, and 3DS1) (Takeshita et al. 2013; Wilson et al. 2000). Triggering activity of NK cells is associated with their receptors' variability and expression and also with the presence of appropriate ligands, which are human leukocyte antigen (HLA) class I molecules for killer immunoglobulin-like receptors (Lanier 1998; Long and Rajagopalan 2000; CarrilloBustamante et al. 2015).

Literature reports tend to focus on the contribution of KIRS to AIDS progression rather than to susceptibility to HIV infection. Most of the researchers emphasize the role of
KIR3DS1 and $3 D L 1$ in AIDS development, in the presence or absence of HLA-B Bw4-80I ligands (Gaudieri et al. 2005; Jiang et al. 2013; Martin et al. 2002, 2007). KIR3DS1 was indicated as a protective factor, in the context of resistance to HIV during different ways of exposure (Boulet et al. 2008; Chavan et al. 2014; Habegger de Sorrentino et al. 2013; Tallon et al. 2014). Among KIR genes involved in susceptibility to HIV, KIR2DS4f was mentioned as an agent associated with accelerated HIV transmission to cohabiting seronegative partners (Merino et al. 2011) and higher risk of intrapartum transmission to children possessing KIR2DS4del (Hong et al. 2013). KIR2DL3 with HLA-C1/C2 combination was elevated in mothers transmitting HIV to their children during delivery and was lower in infected children (Paximadis et al. 2011). Some reports have indicated that HIV transmission was influenced by the compatibility of sexual partners for KIRS and HLA. Incompatibility between them may oblige NK cells from the exposed partner to rejection of incoming cells from the HIV-positive partner (Jennes et al. 2013). Also, presence of KIRs without their ligand, e.g., $2 D L 2 / 2 D L 3$ without $H L A-C 1$ and $3 D L 1$ without $H L A-B w 4$, may inhibit HIV infection, as was observed in the exposed to HIV but uninfected female sex workers in Côte d'Ivoire (Jennes et al. 2006). Furthermore, it seems possible that people with $K I R$ genotypes with more activating genes $(\mathrm{BB}, \mathrm{AB})$ and without ligands for inhibitory KIRs may be better protected against HIV because of the effective NK activation (Jennes et al. 2006, 2011). There has not been enough research to uncover the effects of all KIR genes on HIV infection.

The main aim of the study was to evaluate the influence of genes encoding KIR on susceptibility to HIV-1 infection via the sexual route or intravenous drug injections. We determined the frequency of activating KIR2DS1, 2DS2, 2DS3, 2DS4f, 2DS4del, 2DS5, and 3DS1 and inhibitory KIR2DL1, $2 D L 2,2 D L 3,2 D L 5$, and $3 D L 1$ in the groups of exposed to HIV and HIV-positive (HIV+) or uninfected (EU) people on the background of the blood donors from Lower Silesia region in Poland. During the preparation of the regression model for describing the impact of KIRs on HIV infection, we could not omit other well-known genetic factors (CCR5- $\triangle 32$, and CCR2-64I); thus, they were included in the analysis. To our knowledge, this is the first study in Poland describing the contribution of KIR genes to susceptibility to HIV infection.

\section{Patients and methods}

Patients We included three groups of subjects in our study. The first one (BD) consisted of 98 healthy, HIV-, HCV-, and HBVnegative age-matched blood donors ( 40 women, 58 men) from the Lower Silesia in Poland. They were used as a control of KIR gene frequencies in the studied population. The other two groups comprised persons exposed to HIV but uninfected 
(EU, $n=118$ ) or infected with the virus (HIV+, $n=459)$. The exposure to HIV in each person in EU was long-lasting and repeatable, and seronegativity was confirmed by standard laboratory tests. Of them, $71.2 \%$ were intravenous drug users (EU-IDU; $n=84$ ) with on average 13.7 years history of addiction (1.5 to 36 years); $89.3 \%$ of them were HCV positive. Sexually exposed, long-lasting partners of HIV-infected people (EU-SE; $n=34$ ) were also included in the EU group. Similar subgroups were distinguished among HIV-positive patients of the Department of Infectious Diseases, Liver Diseases, and Acquired Immune Deficiencies (Wroclaw Medical University, Poland). We included in the HIV+ cohort 359 drug addicts (HIV-IDU) and 100 sexually exposed people (HIV-SE). These people were HIV positive and were selected on the basis of a confirmed laboratory diagnosis. Both EU-IDU and HIVIDU were also patients of Monitoring Laboratory for Infections Among Drug Users in Wroclaw, Poland. The detailed characteristics of HIV+ and EU groups are given in Table 1. All procedures performed in studies involving human participants were in accordance with the ethical standards of the institutional and/or national research committee and with the 1964 Helsinki declaration and its later amendments or comparable ethical standards. Informed consent was obtained from all individual participants included in the study. The study was approved by the Commission of Bioethics at Wroclaw Medical University (number of permission KB-182/2005).

Genotyping Genomic DNA was extracted from EDTAanticoagulated blood samples using a QIAamp DNA Blood Midi Kit (Qiagen, Hilden, Germany). CCR5- $\triangle 32$ and CCR2$64 I$ alleles were determined as we described previously (Zwolińska et al. 2013a). KIR genotyping was performed using PCR-SSP according to our previous works (Kuśnierczyk et al. 2015; Mozer-Lisewska et al. 2015). It allowed us to detect the presence of KIR2DS1, 2DS2, 2DS3, 2DS4f, 2DS4del, 2DS5, 3DS1, 2DL1, 2DL2, 2DL3, 2DL5, and $3 D L 1$. We did not discriminate between centromeric and telomeric $2 D L 5$ and $2 D S 3 / 2 D S 5$ forms.

Data analysis The presence of individual KIRs and KIR genotypes (AA, Bx) was calculated as the percentage of positives among all people in the studied groups. Bx represented both $\mathrm{AB}$ and $\mathrm{BB}$ genotypes, and it was characterized by the presence of one or more of the following activating genes: KIR2DS1, 2DS2, 2DS3, 2DS5, and 3DS1. AA genotype was defined by the presence of KIR2DS4 (the full version $2 D S 4 f$ or $2 \mathrm{DS} 4 \mathrm{del}$ ) and absence of mentioned activating genes characteristic for Bx. The differences in specific KIR and KIR genotype frequencies between $\mathrm{BD}, \mathrm{EU}$, and HIV+ groups were evaluated using the $\chi^{2}$ test. Bonferroni correction was performed in the case of multiple comparisons.

Linkage disequilibrium (LD) as a measure of association of nonrandom alleles at two different loci was used to assess the genetic association between KIR gene pairs in studied groups. The strength of the association between the two genes is dependent on $D^{\prime}$ (LD) and $r^{2}$ (relative linkage) value. Their values range from 0 to 1 , where 0 means independence between alleles and 1 reflects complete association between alleles at the two loci.

The evaluation of possible relations between studied KIRS and susceptibility to HIV infection was performed in EU $(n=118)$ and HIV $+(n=459)$ groups, using stepwise logistic regression in the generalized linear model scheme. The equation describing the probability of HIV acquisition during exposure $[P(y=1)]$ is as follows: $P(y=1)=\frac{e^{\beta_{1} x_{1}+\beta_{2} x_{2}+\ldots+\beta_{n} x_{n}+\beta_{0}}}{1+e^{\beta_{1} x_{1}+\beta_{2} x_{2}+\ldots+\beta_{n} x_{n}+\beta_{0}}}$, where $e$ is the base of the natural logarithm, $x_{1}, x_{2}$, and $x_{n}$ are independent variables, $n$ is the number of independent variables, $\beta_{1}, \beta_{2}$, and $\beta_{n}$ are regression coefficients indicating the effect size of independent variables, and $\beta_{0}$ is the intercept. Presence of the studied feature in a given individual was encoded as $x_{n}=1$ and lack of it as $x_{n}=0$. Odds ratio (OR) for, e.g., variable $x_{1}$, is defined by $e^{\beta 1}$. We analyzed the impact of the presence of KIR genes in the context of nongenetic factors, such as sex and route of exposure to HIV (sexual and intravenous drug use). We also analyzed presence of CCR5- $\triangle 32$ and CCR2-64I, as we knew they could influence HIV infection and we wanted to rule out the possibility of misinterpretation in our results. Collinearity of the covariates was assessed with the variance inflation factor (vif), and no collinearity was denoted when vif $<10.0$. Akaike's information criterion (AIC) was used as a measure of fit of the models. Variables were included in the model with $p<0.05$. All statistical analyses were performed using the platform R-CRAN version 3.1.2 (www.r-project.org).

\section{Results}

\section{Distribution of KIRs in the Polish population of HIV-positive and HIV-negative people}

The frequencies of 12 KIRs were evaluated in HIV-positive and HIV-exposed but seronegative people (EU) and blood donors (BD) from Lower Silesia in Poland. We also showed the distribution of KIR genotypes AA (with the only one activating $K I R-2 D S 4$ ) and genotypes with the more varied KIR sets $(\mathrm{Bx})$ (Table 2). No differences in $K I R$ frequencies between $\mathrm{HIV}+$ patients and $\mathrm{BD}$ as well as between EU and BD were detected $(p>0.05)$. However, the comparison of presence of these features in EU and HIV+ groups showed statistically significant differences between frequencies of $2 D L 3$ (95.76 vs. $83.88 \%$, $p=0.010)$ and $2 D L 5$ (34.75 vs. $53.16 \%, p=0.004)$. It may suggest their opposite role in susceptibility to HIV infection-protective against virus acquisition for $2 D L 3$ and promoting infection for $2 D L 5$. There were no statistically 
Table 1 Baseline characteristics of the compared groups of people exposed to HIV, infected (HIV+), or seronegative (EU)

\begin{tabular}{|c|c|c|c|c|c|c|c|c|c|c|c|}
\hline \multirow{2}{*}{$\begin{array}{l}\text { Group } \\
\text { Feature }\end{array}$} & & \multicolumn{5}{|c|}{$\mathrm{HIV}+, n=459$} & \multicolumn{5}{|c|}{$\mathrm{EU}, n=118$} \\
\hline & & \multirow{3}{*}{$\begin{array}{l}\text { Median } \\
29 \\
n\end{array}$} & \multirow{3}{*}{$\begin{array}{l}\text { Sn } \\
6.1 \\
\%\end{array}$} & \multirow{3}{*}{\multicolumn{2}{|c|}{$\begin{array}{lc}\text { Q1 } & \text { Q3 } \\
25 & 36 \\
\text { CI } 95 \%\end{array}$}} & \multirow{3}{*}{$\begin{array}{l}\text { CI } 95 \% \\
28.4 ; 29.6\end{array}$} & \multirow{3}{*}{$\begin{array}{l}\text { Median } \\
29 \\
n\end{array}$} & \multirow{3}{*}{$\begin{array}{l}\mathrm{Sn} \\
5.8 \\
\%\end{array}$} & \multirow{3}{*}{\multicolumn{2}{|c|}{$\begin{array}{ll}\text { Q1 } & \text { Q3 } \\
26 & 34 \\
\text { CI } 95 & \%\end{array}$}} & \multirow{3}{*}{$\begin{array}{l}\text { CI } 95 \% \\
28.0 ; 31.0\end{array}$} \\
\hline Age & & & & & & & & & & & \\
\hline Feature & & & & & & & & & & & \\
\hline \multirow[t]{2}{*}{ Gender } & Women & 153 & 33.3 & \multicolumn{3}{|c|}{$29.0 ; 37.6$} & 39 & 33.1 & \multicolumn{3}{|c|}{$24.6 ; 41.5$} \\
\hline & Men & 306 & 66.7 & \multicolumn{3}{|c|}{$62.4 ; 71.0$} & 79 & 66.9 & \multicolumn{3}{|c|}{$58.5 ; 75.4$} \\
\hline \multirow[t]{2}{*}{ Sexual exposure (SE) } & Yes & 100 & 21.8 & \multirow{2}{*}{\multicolumn{3}{|c|}{$18.0 ; 25.6$}} & 34 & 28.8 & \multirow{2}{*}{\multicolumn{3}{|c|}{$20.6 ; 37.0$}} \\
\hline & No & 359 & 78.2 & & & & 84 & 71.2 & & & \\
\hline \multirow[t]{2}{*}{ Heterosexual exposure (HT) } & Yes & 61 & 13.3 & \multirow{2}{*}{\multicolumn{3}{|c|}{$10.2 ; 16.4$}} & 32 & 27.1 & \multirow{2}{*}{\multicolumn{3}{|c|}{$19.1 ; 35.1$}} \\
\hline & No & 398 & 86.7 & & & & 86 & 72.9 & & & \\
\hline \multirow[t]{2}{*}{ Homosexual exposure (HO) } & Yes & 35 & 7.6 & \multirow{2}{*}{\multicolumn{3}{|c|}{$5.2 ; 10.1$}} & 2 & 1.7 & \multirow{2}{*}{\multicolumn{3}{|c|}{$0.0 ; 4.0$}} \\
\hline & No & 424 & 92.4 & & & & 116 & 98.3 & & & \\
\hline \multirow[t]{2}{*}{ Homo/heterosexual exposure (HO/HT) } & Yes & 4 & 0.9 & \multirow{2}{*}{\multicolumn{3}{|c|}{$0.0 ; 1.7$}} & 0 & 0.0 & \multirow{2}{*}{\multicolumn{3}{|c|}{$0.0 ; 0.0$}} \\
\hline & No & 455 & 99.1 & & & & 118 & 100.0 & & & \\
\hline \multirow[t]{2}{*}{ Intravenous drug users (IDU) } & Yes & 359 & 78.2 & \multirow{2}{*}{\multicolumn{3}{|c|}{$74.4 ; 82.0$}} & 84 & 71.2 & \multirow{2}{*}{\multicolumn{3}{|c|}{$63.0 ; 79.4$}} \\
\hline & No & 100 & 21.8 & & & & 34 & 28.8 & & & \\
\hline \multirow[t]{2}{*}{$\mathrm{HCV}^{\mathrm{a}}$} & Yes & 355 & 77.9 & \multirow{2}{*}{\multicolumn{3}{|c|}{$74.0 ; 81.7$}} & 77 & 68.1 & \multirow{2}{*}{\multicolumn{3}{|c|}{$59.6 ; 76.7$}} \\
\hline & No & 101 & 22.1 & & & & 36 & 31.9 & & & \\
\hline
\end{tabular}

$S n$ - average dispersion, $Q 1, Q 3$ - 1st and 3rd quartiles, respectively, CI $95 \%$ - $95 \%$ confidence interval

${ }^{\mathrm{a}}$ There were no data for HCV status for three individuals in HIV+ and five in EU group

significant differences in genotypes $\mathrm{AA}$ and $\mathrm{Bx}$ between groups $(p>0.05)$. Analysis of LD between tested KIRs in HIV-positive, EU, and BD is shown in Table 3. It revealed similarity between LD of some gene pairs in all groups (e.g., high LD for KIR2DS2 and 2DL2). It also indicated differences between groups, e.g., decreased LD for 2DS1 and $3 D S 1$ in HIV+ and EU in comparison to background population and reduced $L D$ for pair $2 D L 3$ and $2 D L 1$ in $\mathrm{HIV}+$ individuals compared to EU and BD.

\section{Effects of $K I R$ and chemokine receptor genes on susceptibility to HIV infection}

We analyzed the effects of KIRs (Table 2) on susceptibility to HIV infection by comparison of their distribution in EU and HIV-positive people. Logistic regression was used for evaluation of probability of HIV infection depending on KIR genes in case of sexual exposure or intravenous drug use. We also included in the model the presence of CCR5- $\triangle 32$ and CCR2-

Table 2 Frequencies of killer cell immunoglobulin-like receptor genes $(K I R)$ and genotypes AA and Bx in studied groups

\begin{tabular}{|c|c|c|c|c|c|c|c|c|c|c|c|c|c|c|c|}
\hline & & $2 D S 1$ & $2 D S 2$ & $2 D S 3$ & $2 D S 4 f$ & 2DS4del & $2 D S 5$ & $3 D S 1$ & $2 D L 1$ & $2 D L 2$ & $2 D L 3$ & $2 D L 5$ & $3 D L 1$ & Genotypes AA & Genotypes Bx \\
\hline \multirow[t]{2}{*}{$\mathrm{BD}, n=98$} & $n$ & 34 & 47 & 24 & 40 & 84 & 28 & 34 & 97 & 46 & 91 & 43 & 94 & 33 & 65 \\
\hline & $\%$ & 34.69 & 47.96 & 24.49 & 40.82 & 85.71 & 28.57 & 34.69 & 98.98 & 46.94 & 92.86 & 43.88 & 95.92 & 33.67 & 66.33 \\
\hline \multirow[t]{2}{*}{$\mathrm{EU}, n=118$} & $n$ & 35 & 50 & 24 & 43 & 101 & 27 & 37 & 115 & 53 & 113 & 41 & 115 & 44 & 74 \\
\hline & $\%$ & 29.66 & 42.37 & 20.34 & 36.44 & 85.59 & 22.88 & 31.36 & 97.46 & 44.92 & 95.76 & 34.75 & 97.46 & 37.29 & 62.71 \\
\hline \multirow[t]{2}{*}{$\mathrm{HIV}+, n=459$} & $n$ & 191 & 258 & 156 & 163 & 383 & 124 & 172 & 434 & 257 & 385 & 244 & 437 & 141 & 318 \\
\hline & $\%$ & 41.61 & 56.21 & 33.99 & 35.51 & 83.44 & 27.02 & 37.47 & 94.55 & 55.99 & 83.88 & 53.16 & 95.21 & 30.72 & 69.28 \\
\hline OR & & 1.69 & 1.75 & 2.02 & 0.96 & 0.85 & 1.25 & 1.31 & 0.45 & 1.56 & 0.23 & 2.13 & 0.52 & 1.34 & \\
\hline \multirow[t]{2}{*}{ CI $95 \%$} & & 1.09 & 1.16 & 1.24 & 0.63 & 0.48 & 0.77 & 0.85 & 0.13 & 1.04 & 0.09 & 1.40 & 0.15 & 0.88 & \\
\hline & & 2.61 & 2.63 & 3.29 & 1.46 & 1.50 & 2.01 & 2.02 & 1.53 & 2.34 & 0.58 & 3.25 & 1.76 & 2.05 & \\
\hline$p^{*}$ & & 0.213 & 0.087 & 0.052 & 1.000 & 1.000 & 1.000 & 1.000 & 1.000 & 0.378 & 0.010 & 0.004 & 1.000 & 0.173 & \\
\hline
\end{tabular}

$B D$ - blood donors from Lower Silesia region of Poland, $E U$ - exposed, $H I V$-1-seronegative, $H I V+$ - exposed to HIV and seropositive, $2 D S 4 f$ - full-length KIR2DS4 gene, 2DS4del - KIR2DS4 with 22 base pair deletion, OR - odds ratio, based on the comparison of EU and HIV, CI $95 \%$ - $95 \%$ confidence interval, $B x$ - represents $K I R$ genotypes $\mathrm{AB}$ and $\mathrm{BB}$

${ }^{*} p$ value after Bonferroni correction (in case of comparison of KIRs frequencies) 


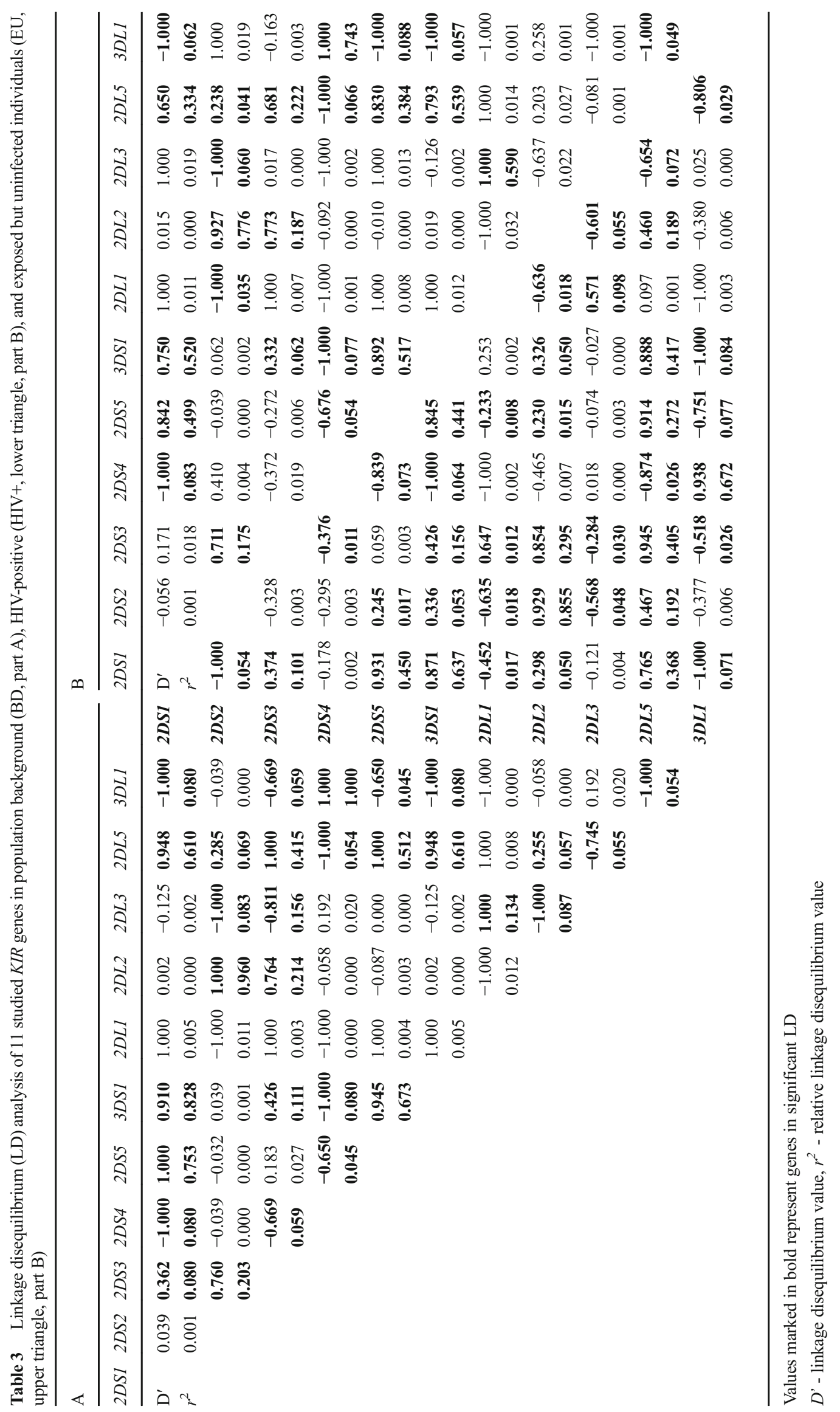


64I. They were analyzed to avoid misinterpretation of effects of KIRs which could be caused by chemokine receptors (O'Brien and Moore 2000; Zapata et al. 2013; Zwolińska et al. 2013a). We did not find collinearity between variables included to the model (vif $<10.0$, Table 4 ), so we could consider their effects independently. We did not prove a link between KIR2DS2, 2DS3, 2DS4f, 2DS4del, 2DS5, 2DL3, 2DL5, and $3 D L 1$ with susceptibility to HIV infection. The genetic factors involved in susceptibility to HIV infection are shown in Table 4. Analysis confirmed a strong protective effect of CCR5- $\Delta 32(p=0.006)$, especially in females $(p=0.026)$. CCR2-64I was also found to be a protective factor ( $p=0.032$ ). Among KIR genes, $2 D L 3$ was found to be a factor reducing the risk of HIV infection $(p=0.015)$ in contrast to $2 D L 5$ ( $p=0.013)$, which was found to be an agent promoting infection. The harmful role of $2 D L 2$ was observed in women $(p=0.040)$ and $2 D S 1$ in case of exposure to HIV via drug injections $(p=0.022)$. 3DS1 had a protective effect during exposure to HIV among IDUs $(p=0.019)$.

The presence of CCR5- $\triangle 32$ mutation had the biggest effect on HIV infection occurrence, as might have been expected. This allele was present in $22.0 \%$ of EU and $16.6 \%$ of HIV+ people. Risk of infection in people who had this allele was about four times lower $(\mathrm{OR}=0.25)$ than in people with the wild version of the CCR5. This relation was even stronger in women $\left(\beta_{C C R 5-\triangle 32: \text { women }}=-1.212\right)$, resulting in more than 13 times lower risk of HIV infection among CCR5- $\triangle 32$ female carriers $\left(\mathrm{e}^{-1.3982-1.2123}=0.074\right)$. However, the beneficial influence of $C C R 5-\triangle 32$ was six times weaker in IDUs $(\mathrm{OR}=6.02)$ than in SE people. Weaker than for $C C R 5-\triangle 32$, but still a protective effect against HIV infection was observed for CCR2-64I. This allele was present in $28.8 \%$ of EU and
$22.2 \%$ of HIV+ individuals. The $C C R 2-64 I$ reduced the risk of HIV infection by about $41 \%(\mathrm{OR}=0.59)$.

Logistic regression revealed that the presence of KIR $2 D L 3$ decreased the risk of HIV infection by about $70 \%$ $(\mathrm{OR}=0.30)$. The opposite effect was observed for $2 D L 5$, which increased this risk more twofold $(\mathrm{OR}=2.13)$ and $2 D L 2$, but only in women $(\mathrm{OR}=2.15)$.

A contradictory role of KIR2DS1 and 3DS1 on susceptibility to HIV on the intravenous drug use route was found. $2 D S 1$ positive drug addicts had three times higher risk of HIV infection $(\mathrm{OR}=3.03)$ than the negative ones had. On the other hand, they had more than three times lower risk of infection when they had the $3 D S 1$ gene $(\mathrm{OR}=0.30)$.

\section{Distribution of allelic versions of genes $K I R 2 D L 2 / 2 D L 3$ and $K I R 3 D L 1 / 3 D S 1$ in HIV-positive and HIV-negative people}

We analyzed the distribution of two pairs of KIR genes segregated as alleles in $\mathrm{HIV}+, \mathrm{EU}$, and BD groups (KIR3DL1, 3DS1 and KIR2DL2, 2DL3 alleles) (Table 5). Every individual had at least one of the $3 D L 1$ or $3 D S 1$ alleles. One of the EU individuals $(0.85 \%)$ and 13 of HIV+ $(2.83 \%)$ had neither $2 D L 2$ nor $2 D L 3$. No differences in frequencies of combinations $3 D L 1 / 3 D S 1,3 D L 1$ or $3 D S 1$ alone as well as $2 D L 2 /$ $2 D L 3,2 D L 2$ or $2 D L 3$ alone between $\mathrm{HIV}+$ patients and BD as well as between EU and BD were detected ( $p>0.05)$. 2DL2 without $2 D L 3$ was detected in $3.39 \%$ of the EU and in $13.29 \%$ of the HIV+ group, which indicated the harmful role of $2 D L 2$ in case of exposure to HIV. $2 D L 2$ presence with absence of $2 D L 3$ resulted in more than four times higher risk of HIV acquisition $(\mathrm{OR}=4.37, p=0.005)$. A protective effect

Table 4 Role of studied genetic factors in susceptibility to HIV infection

\begin{tabular}{|c|c|c|c|c|c|c|c|}
\hline Factors & Impact $^{\mathrm{a}}$ & $\beta$ & OR & CI $95 \%$ & & $p$ value & vif \\
\hline$C C R 5-\triangle 32$ & $\downarrow$ & -1.398 & 0.25 & 0.09 & 0.68 & 0.006 & 3.394 \\
\hline CCR2-64I & $\downarrow$ & -0.531 & 0.59 & 0.36 & 0.96 & 0.032 & 1.040 \\
\hline$K I R 2 D L 3$ & $\downarrow$ & -1.201 & 0.30 & 0.10 & 0.72 & 0.015 & 1.035 \\
\hline KIR2DL5 & $\uparrow$ & 0.757 & 2.13 & 1.19 & 3.96 & 0.013 & 1.873 \\
\hline$K I R 2 D L 2$ in women ${ }^{\mathrm{b}}$ & $\uparrow$ & 0.767 & 2.15 & 1.08 & 4.70 & 0.040 & 1.190 \\
\hline$K I R 2 D S 1$ in IDU $^{\mathrm{c}}$ & $\uparrow$ & 1.109 & 3.03 & 1.21 & 8.13 & 0.022 & 3.486 \\
\hline$K I R 3 D S 1$ in IDU ${ }^{\mathrm{c}}$ & $\downarrow$ & -1.215 & 0.30 & 0.10 & 0.80 & 0.019 & 4.105 \\
\hline$C C R 5-\triangle 32$ in $\mathrm{IDU}^{\mathrm{c}}$ & $\uparrow$ & 1.796 & 6.02 & 2.04 & 18.55 & 0.001 & 2.902 \\
\hline$C C R 5-\triangle 32$ in women ${ }^{b}$ & $\downarrow$ & -1.212 & 0.30 & 0.10 & 0.86 & 0.026 & 1.860 \\
\hline Intercept & - & 2.297 & - & - & - & $6.88 \mathrm{e}-06$ & - \\
\hline
\end{tabular}

All data come from one regression model including all factors listed in the Table 3 . There was no collinearity between the variables (vif $<10.0$ ) $\uparrow$ - infection risk increased, $\downarrow$ - infection risk reduced, $\beta$ - coefficient in regression model, $C I 95$ - $\% 95 \%$ confidence interval, $O R$ - odds ratio, vif - variance inflation factor, $I D U$ - intravenous drug users

${ }^{a}$ Impact on susceptibility to HIV infection

${ }^{\mathrm{b}}$ Compared with men

${ }^{\mathrm{c}}$ Compared with individuals sexually exposed to HIV 
of the presence of $2 D L 3$ without $2 D L 2$ was indicated because of overrepresentation in EU compared with HIV+ (54.24 vs. $41.18 \%$, respectively). Hence, it decreased the risk of HIV infection by $41 \%(\mathrm{OR}=0.59, p=0.022)$. $2 D L 2 / 2 D L 3$ heterozygosity was almost equally represented in both groups (Table 5).

\section{Discussion}

Our data highlights the impact of genes encoding KIR on the risk of HIV infection in case of sexual exposure or intravenous drug use. Presence of seven activating (2DS1, 2DS2, 2DS3, $2 D S 4 f, 2 D S 4 d e l, 2 D S 5,3 D S 1)$ and five inhibitory (2DL1, 2DL2, 2DL3, 2DL5, 3DL1) KIRs was determined in the group of $\mathrm{HIV}+, \mathrm{EU}$, and in healthy BD. The frequencies of KIRs in the BD group did not differ significantly from those given by the Allele Frequency Net Database for the Polish population (González-Galarza et al. 2015).

The differences in some KIR frequencies in EU and HIV+ groups indicated their involvement in susceptibility to HIV infections, e.g., KIR2DL3 and 2DL5 (Table 2). These differences prompted us to perform more comprehensive analysis of the impact of KIRs on the risk of HIV infection depending on the route of exposure. We also included in the analysis alleles $C C R 5-\triangle 32$ and CCR2-64I. Chemokine receptors are used as main (CCR5) or alternative (CCR2, CCR3, CXCR4, and other) co-receptors for HIV, and it is known that some of their allelic versions may impact HIV infection (ArenzanaSeisdedos and Parmentier 2006; O’Brien and Moore 2000; Zwolińska 2009).

Logistic regression performed in our study revealed some important relationships between tested genetic factors and susceptibility to HIV infection (Table 3 ). It was no surprise that $C C R 5-\triangle 32$ had a protective effect against HIV and decreased infection risk about fourfold. There has been a lot of research in recent years confirming restriction of HIV infection by this allele (Hütter et al. 2009; Mahajan et al. 2010; O'Brien and Moore 2000; Zapata et al. 2013; Zwolińska et al. 2013a and references therein). Our analysis showed that the effect of CCR5- $\triangle 32$ is particularly strong in females, but its favorable impact is much lower in IDUs than in sexually exposed CCR5- $\triangle 32$ carriers (Table 3 ). It may be associated with high viral load during exposure by direct intravenous injections, decreased immunity, and the poor general health condition of drug addicts. In our previous work, based partially on the same patients, we proved the beneficial role of CCR5- $\triangle 32$ during the heterosexual route of infection (Zwolińska et al. 2013a), but no effect was observed in the case of IDUs. Most of the available data showed no effect of CCR2-64I mutation on susceptibility to HIV infection (Mahajan et al. 2010; O’Brien and Moore 2000; Tan et al. 2010), indicating rather its involvement in the slowing of AIDS progression (Kaslow et al. 2005; O'Brien and Moore 2000; Vieira et al. 2011; $\mathrm{Xu}$ et al. 2010). However, there are some reports supporting a protective role of CCR2-64I against vertical HIV transmission (Mabuka et al. 2009) or via sexual exposure (Zapata et al. 2013). Our present analysis showed a protective effect of CCR2-64I against HIV acquisition. This allele resulted in a reduction of HIV infection risk by about $41 \%$ regardless of the way of exposure (Table 3).

It is generally known that efficient activation of NK cells, their cytolytic activity, and cytokine secretion is necessary for anti-HIV reactions (Boulet et al. 2010; Jennes et al. 2006; Martin and Carrington 2013; Tiemessen et al. 2011). That is why KIR genotype AA may be harmful in the context of exposure to HIV because of the limited possibility for NK cell stimulation (only one activating gene, KIR2DS4, often defective 2DS4del, is present in AA genotype), whereas more diverse genotypes $(\mathrm{BB}$ or $\mathrm{AB})$, with more activating genes or
Table 5 Frequencies of allelic version of genes $K I R 3 D L 1 / 3 D S 1$ and KIR $2 D L 2 / 2 D L 3$ in HIVpositive and HIV-negative people

\begin{tabular}{|c|c|c|c|c|c|c|c|}
\hline Groups & & $3 D L 1$ & $3 D L 1 / 3 D S 1$ & $3 D S 1$ & $2 D L 2^{\mathrm{a}}$ & $2 D L 2 / 2 D L 3^{\mathrm{a}}$ & $2 D L 3^{\mathrm{a}}$ \\
\hline \multirow{2}{*}{$\mathrm{BD}, n=98$} & $n$ & 64 & 30 & 4 & 7 & 39 & 52 \\
\hline & $\%$ & 65.31 & 30.61 & 4.08 & 7.14 & 39.80 & 53.06 \\
\hline \multirow{2}{*}{$\mathrm{EU}, n=118$} & $n$ & 81 & 34 & 3 & 4 & 49 & 64 \\
\hline & $\%$ & 68.65 & 28.81 & 2.54 & 3.39 & 41.52 & 54.24 \\
\hline \multirow[t]{2}{*}{$\mathrm{HIV}+, n=459$} & $n$ & 287 & 150 & 22 & 61 & 196 & 189 \\
\hline & $\%$ & 62.53 & 32.68 & 4.79 & 13.29 & 42.70 & 41.18 \\
\hline OR & & 0.76 & 1.20 & 1.93 & 4.37 & 1.05 & 0.59 \\
\hline \multirow[t]{2}{*}{ CI $95 \%$} & & 0.49 & 0.77 & 0.57 & 1.56 & 0.70 & 0.39 \\
\hline & & 1.17 & 1.87 & 6.56 & 12.27 & 1.58 & 0.89 \\
\hline$p$ & & 0.436 & 0.844 & 0.569 & 0.005 & 1.636 & 0.022 \\
\hline
\end{tabular}

$p$ Value after Bonferroni correction

$B D$ - blood donors from Lower Silesia region of Poland, $E U$ - exposed, HIV-1-seronegative, HIV+ exposed to HIV and seropositive, $O R$ - odds ratio, based on the comparison of EU and HIV, CI $95 \%$ - $95 \%$ confidence interval

${ }^{a}$ One of EU individuals ( $\left.0.85 \%\right)$ and $13 \mathrm{HIV}+$ individuals $(2.83 \%)$ had neither $2 D L 2$ nor $2 D L 3$ 
any KIR genotypes but with no presence of ligands for inhibitory KIRs, should provide sufficient NK cell activation and thus protection against HIV (Jennes et al. 2006, 2011). We did not prove any beneficial effect of more varied genotypes of KIRs, and there were no differences in genotypes AA or $\mathrm{Bx}$ frequencies between $\mathrm{EU}$ and $\mathrm{HIV}+$ people (Table 2). On the other hand, O'Connell et al. suggested that strong NK cellmediated inhibition of viral replication was not absolutely necessary for the immunological control of HIV in a group of elite suppressors (ES) long-term controlling HIV viremia. Some of their ES patients with A haplotype had stronger NKderived HIV inhibition than patients with haplotype B (O'Connell et al. 2009). Moreover, Gaudieri et al. suggested the association between haplotype B and faster CD4+ cell count decrease leading to the progression of HIV infection towards AIDS (Gaudieri et al. 2005). It might indicate that a more diverse set of KIR on NK cells (haplotype B) makes their activity regulation more difficult.

Our results allowed us to draw some unique conclusions about specific KIR effects on susceptibility to HIV (Table 3). Most of literature reports have focused on KIR3DSI and $3 D L 1$ and their effects on HIV infection course depending on the presence of the ligand HLA-B Bw4-80I (Alter et al. 2007; Gaudieri et al. 2005; Jiang et al. 2013; Martin et al. 2002, 2007). We found that the risk of HIV infection in individuals with KIR3DS1 was more than three times lower in IDUs than in SE people. KIR3DS1, especially when present on both chromosomes, was indicated as a protective factor during different ways of infection (Boulet et al. 2008; Chavan et al. 2014; Habegger de Sorrentino et al. 2013; Tallon et al. 2014). Our results are particularly consistent with the work of the group of Tallon, who demonstrated that the time of seroconversion in long-term repeatedly HIV-exposed people was significantly longer in homozygotes KIR3DS1/3DS1 than heterozygotes KIR3DS1/3DL1. This situation occurred only among injection drug users, not in the case of initially HIVnegative partners of serodiscordant couples (Tallon et al. 2014). Mechanisms of positive action of KIR3DS1 in antiHIV action are still unknown. Most explanations assume the effective activation of NK cells against HIV proteins via KIR3DS1 interaction with its putative ligand HLA-B Bw480I. It still remains controversial because there is no evidence that HLA-B Bw4-80I, a well-known ligand of inhibitory KIR3DL1, may also serve as a functional ligand for KIR3DS1 (Martin and Carrington 2013; Martin et al. 2002, 2007; Tallon et al. 2014). Moreover, it seems that the activation of NK cells via KIR3DS1 and 3DL1 is dependent on what was presented by their peptide ligands, as it was shown by O'Connor et al. (2015).

Our findings indicated that the positive effects of $K I R 3 D S 1$ among drug addicts were diminished by the presence of KIR2DS1. KIR2DS1-positive IDUs had more than three times higher risk of HIV acquisition than did SE individuals. To date, there has been no report about KIR2DS1 contribution to HIV infection. Both KIR3DS1 and 2SD1 trigger NK cell function into their activation, but it occurs after binding different ligands. KIR2DS1 binds HLA-C2 (Lys80), but with low affinity, and its high-affinity ligand is not known (Martin and Carrington 2013). It is possible that expression of KIR2DS1 on NK cells does not provide their sufficient activation against HIV. Both $2 D S 1$ and $3 D S 1$ genes (characteristic for telomeric B haplotype) are in almost perfect LD in our $\mathrm{BD}$ group $\left(D^{\prime}=0.910 ; r^{2}=0.828\right)$, what is concordant with the data for Polish population (González-Galarza et al. 2015). Is interesting to note that LD for this pair is decreased in EU and HIV+ individuals (see Table 3). 2DS1 is overrepresented in HIV+. Both groups are enriched for haplotypes with $2 D S 1$ but without $3 D S 1$ (5.1\% for EU and 7.0 for $\mathrm{HIV}+$ ), and, in the EU group, there are more haplotypes with $3 D S 1$ but without $2 D S 1$ than in the HIV+ one (6.8 vs. $2.8 \%$, respectively).

Another interesting finding was associated with KIR2DL2, $2 D L 3$, and $2 D L 5$ (Table 4). We detected the protective effect of $2 D L 3$ against HIV acquisition and the harmful role of $2 D L 5$ and $2 D L 2$ but only in females. Both 2DL2 and 2DL3 receptors bind to HLA-C1 (Asn80) and transfer an inhibitory signal to NK cells, but 2DL2 has higher affinity to its ligand than 2DL3 (Frazier et al. 2013). The ligand for 2DL5 has not been identified yet (Martin and Carrington 2013). Our results are not in line with investigations by Jennes et al. $(2006,2013)$ and Paximadis et al. (2011). Jennes et al. (2006) reported significantly higher frequencies of KIR2DL2 and $2 D L 5$ in a group of HIV-exposed but seronegative (ESN) than in HIVseropositive (SP) female sex workers. KIR2DL2/2DL3 heterozygotes were more frequent in the ESN (62\%) than in the SP $(25 \%)$ individuals. The opposite situation was seen in the case of homozygous $2 D L 3$, which was present in $14 \%$ of ESN and $60 \%$ of SP individuals. Furthermore, HIV restriction was observed in ESN subjects who were carriers of inhibitory KIR2DL2/2DL3 but not their ligand, HLA-C1. KIR2DL3/ $2 D L 3$ homozygotes with $H L A-C 1$ were characteristic for HIV-seropositive female sex workers (Jennes et al. 2006), which could be due to NK cell inhibition. Paximadis and coworkers (2011) reported an increased frequency of homozygosity of KIR2DL3 alone and in combination with $H L A-C 1 /$ $C 2$ in mothers transmitting HIV to their children perinatally (TR) compared with mothers who did not transmit the virus (NT). On the other hand, TR had a lower frequency of the heterozygous combination KIR2DL2/2DL3 than NT, suggesting its protective role of $2 D L 2$ against HIV perinatal transmission to the children. Paximadis et al. (2011) reported that $K I R 2 D L 3$ in combination with $H L A-C 1$ and homozygosity for $K I R 2 D L 3$ with $H L A C 1 / C 2$ were both lower in infected children (INF) compared to EU children. This corresponds with our results indicating the anti-HIV effect of KIR2DL3. 
The impact of studied KIR on the susceptibility to HIV in our groups may be associated with specific KIR haplotypes. KIR2DL3 is a part of centromeric haplotype A, so its protective character could be also mediated by $2 D L 1$ from this haplotype. However, $2 D L 1$ may be also located in centromeric $\mathrm{B}$ haplotypes, together with $2 D L 5 B$ and $2 D L 2$. Our genotyping system did not allow for discrimination between centromeric $2 D L 5 B$ and telomeric $2 D L 5 A$, and we could not determine which version was responsible for the unbeneficial effect on susceptibility to HIV. The impact of $2 D L 5 B$ could be also associated with $2 D L 1$ and $2 D L 2$, and we showed harmful action of $2 D L 2$ in the case of a woman. High positive LD between $2 D L 2$ and $2 D S 2$ in HIV+ and EU (see Table 3) suggested a similar role for both these genes, but we have not proven it in the regression analysis. Contribution of $2 D L 1$ seems to be unclear due to the possibility of its location in both centromeric $\mathrm{A}$ and $\mathrm{B}$ regions. Hilton et al. showed that $2 D L 1$ encoded by centromeric $\mathrm{A}$ alleles binds his ligands HLA-C2 with greater avidity than $2 D L 1$ on the centromeric B part (Hilton et al. 2015). If the negative effect of $2 D L 5$ is associated with telomeric B alleles, it may be also related with $2 D S 1$, the harmful role of which we showed in the IDU group. However, haplotypic association with susceptibility to HIV demands further clarification.

There is no doubt that NK cells are very important in immunity and that KIR are responsible for modulation of NK cells' anti-HIV activity. However, it is quite difficult to draw general conclusions about the impact of specific KIRs on susceptibility and the course of HIV infection. Such analysis is specifically difficult because of the high diversity of these genes and because of HIV variability and its defensive strategies. Certainly, specific KIR genes may be present in many combinations as one of the 398 KIR genotypes identified or others not discovered yet (González-Galarza et al. 2015; Takeshita et al. 2013). Furthermore, they are very polymorphic; e.g., the most polymorphic KIR3DL1/3DS1 locus has more than 70 inhibitory and more than 15 activating alleles (Robinson et al. 2013). Some alleles may be expressed at different levels; e.g., KIR3DL1 can be expressed at a high (allele $3 D L 1^{*} \mathrm{~h}$ ) or low level (allele $3 D L 1^{*} l$ ) or even is absent on the cell surface because of internalization in the cytoplasm (allele 3DL1*004) (Martin et al. 2007). The expression of KIRs on the NK surface is highly varied, and two individuals may have different KIR panels on their NK, despite having the same KIR gene repertoire (Gardiner 2008). Besides that, the strength of NK activation or inhibition is associated with receptor-ligand relations, and even different alleles of the same gene may bind their ligands with different avidity (Hilton et al. 2015). Moreover, the activity of NK cells is dependent not only on the balance of activating/inhibitory signaling derived from KIRs but also on other receptors, e.g., NKG2, which were also found to be an HIV restriction factor (Fogli et al. 2008). The diversity in genes encoding NK cell receptors, including in different geographic populations and complexity of NK reactions during HIV infection, is probably the reason for the inconsistent or divergent results of research in this field.

This work supports the beneficial role of activating KIR $3 D S 1$ and inhibitory $2 D L 3$ and the unfavorable effect of activating $2 D S 1$, inhibitory $2 D L 5$, and $2 D L 2$ genes in resistance to HIV infection. These findings are original and unique. According to our knowledge, this study for the first time takes into consideration the impact of KIR genes on susceptibility to HIV in the Poland population. Because of this, this work has some limitations, such as the relatively small study groups and the impossibility to compare our results with other analyses in the Polish general population. Moreover, we plan to extend our research on the impact of KIR and their HLA ligand combinations as well as on high-resolution KIR genotyping with regard to alleles with high and low expression on the NK cell surface, which requires further investigations.

In summary:

1. CCR5- $\triangle 32$ and $C C R 2-64 I$ alleles protected against HIV infection.

2. KIR2DL3 was found to be a protective factor and $K I R 2 D L 5$ as a factor promoting HIV infection.

3. KIR3DS1 decreased and KIR2DS1 increased the risk of HIV infection during intravenous drug injection but not via sexual exposure.

4. KIR2DL2 was found to be a factor increasing the risk of HIV infection in females.

Acknowledgments The work reported here is part of a project entitled "The genetic factors influenced the susceptibility and the course of HIV-1 infection" and was supported by the Polish Ministry of Science and Higher Education (grant nos. 2 P05B 15229 and N N402 180434; www.nauka.gov.pl), The Marshal Office of Lower Silesia Voivodeship (grant for PhD students II/2009; http://www.umwd.dolnyslask.pl), and Wroclaw Centre of Biotechnology, under the Leading National Research Centre (KNOW) program for years 2014-2018. We are grateful to Paulina Grabia, MSc, Magdalena Janicka, MSc, and Jakub Grzeszczuk, MSc, for help in KIR genotyping.

Open Access This article is distributed under the terms of the Creative Commons Attribution 4.0 International License (http:// creativecommons.org/licenses/by/4.0/), which permits unrestricted use, distribution, and reproduction in any medium, provided you give appropriate credit to the original author(s) and the source, provide a link to the Creative Commons license, and indicate if changes were made.

\section{References}

Alter G, Martin MP, Teigen N, Carr WH, Suscovich TJ, Schneidewind A, Streeck H, Waring M, Meier A, Brander C et al (2007) Differential natural killer cell-mediated inhibition of HIV-1 replication based on distinct KIR/HLA subtypes. J Exp Med 204:3027-3036 
Arenzana-Seisdedos F, Parmentier M (2006) Genetics of resistance to HIV infection: role of co-receptors and co-receptor ligands. Semin Immunol 18:387-403

Bhardwaj N, Maldarelli F, Mellors J, Coffin JM (2014) HIV-1 infection leads to increased transcription of human endogenous retrovirus HERV-K (HML-2) proviruses in vivo but not to increased virion production. J Virol 88:11108-11120

Boulet S, Sharafi S, Simic N, Bruneau J, Routy J-P, Tsoukas CM, Bernard NF (2008) Increased proportion of KIR3DS1 homozygotes in HIVexposed uninfected individuals. AIDS 22:595-599

Boulet S, Song R, Kamya P, Bruneau J, Shoukry NH, Tsoukas CM, Bernard NF (2010) HIV protective KIR3DL1 and HLA-B genotypes influence NK cell function following stimulation with HLAdevoid cells. J Immunol 184:2057-2064

Carrillo-Bustamante P, Keşmir C, de Boer RJ (2015) The evolution of natural killer cell receptors. Immunogenetics. doi:10.1007/s00251015-0869-7

Chavan VR, Chaudhari D, Ahir S, Ansari Z, Mehta P, Mania-Pramanik J (2014) Variations in KIR genes: a study in HIV-1 serodiscordant couples. BioMed Res Int 2014:891402

Ding D-L, Liu S-J, Zhu H-Z (2011) Association between the CCR2Val64Ile polymorphism and susceptibility to HIV-1 infection: a meta-analysis. Mol Med Rep 4:181-186

Farberov L, Herzig E, Modai S, Isakov O, Hizi A, Shomron N (2015) MicroRNA regulation of $\mathrm{p} 21$ and TASK1 cellular restriction-factors enhances HIV-1 infection. J Cell Sci 128:1607-1616

Faure M, Long EO (2002) KIR2DL4 (CD158d), an NK cell-activating receptor with inhibitory potential. J Immunol 168:6208-6214

Fogli M, Mavilio D, Brunetta E, Varchetta S, Ata K, Roby G, Kovacs C, Follmann D, Pende D, Ward J et al (2008) Lysis of endogenously infected CD4+ T cell blasts by rIL-2 activated autologous natural killer cells from HIV-infected viremic individuals. PLoS Pathog 4, e1000101

Frazier WR, Steiner N, Hou L, Dakshanamurthy S, Hurley CK (2013) Allelic variation in KIR2DL3 generates a KIR2DL2-like receptor with increased binding to its HLA-C ligand. J Immunol 190:61986208

Gardiner CM (2008) Killer cell immunoglobulin-like receptors on NK cells: the how, where and why. Int J Immunogenet 35:1-8

Gaudieri S, DeSantis D, McKinnon E, Moore C, Nolan D, Witt CS, Mallal SA, Christiansen FT (2005) Killer immunoglobulin-like receptors and HLA act both independently and synergistically to modify HIV disease progression. Genes Immun 6:683-690

González-Galarza FF, Takeshita LYC, Santos EJM, Kempson F, Maia MHT, da Silva ALS, Silva ALTE, Ghattaoraya GS, Alfirevic A, Jones AR et al (2015) Allele frequency net 2015 update: new features for HLA epitopes, KIR and disease and HLA adverse drug reaction associations. Nucleic Acids Res 43:D784-D788

Graef T, Moesta AK, Norman PJ, Abi-Rached L, Vago L, Older Aguilar AM, Gleimer M, Hammond JA, Guethlein LA, Bushnell DA et al (2009) KIR2DS4 is a product of gene conversion with KIR3DL2 that introduced specificity for HLA-A*11 while diminishing avidity for HLA-C. J Exp Med 206:2557-2572

Habegger de Sorrentino A, Sinchi JL, Marinic K, López R, Iliovich E (2013) KIR-HLA-A and B alleles of the Bw4 epitope against HIV infection in discordant heterosexual couples in Chaco Argentina. Immunology 140:273-279

Hilton HG, Guethlein LA, Goyos A, Nemat-Gorgani N, Bushnell DA, Norman PJ, Parham P (2015) Polymorphic HLA-C receptors balance the functional characteristics of KIR haplotypes. J Immunol 195:3160-3170

Hong HA, Paximadis M, Gray GE, Kuhn L, Tiemessen CT (2013) KIR2DS4 allelic variants: differential effects on in utero and intrapartum HIV-1 mother-to-child transmission. Clin Immunol 149:498-508
Hütter G, Nowak D, Mossner M, Ganepola S, Müssig A, Allers K, Schneider T, Hofmann J, Kücherer C, Blau O et al (2009) Longterm control of HIV by CCR5 Delta32/Delta32 stem-cell transplantation. N Engl J Med 360:692-698

Jennes W, Verheyden S, Demanet C, Adjé-Touré CA, Vuylsteke B, Nkengasong JN, Kestens L (2006) Cutting edge: resistance to HIV-1 infection among African female sex workers is associated with inhibitory KIR in the absence of their HLA ligands. J Immunol 177:6588-6592

Jennes W, Verheyden S, Demanet C, Menten J, Vuylsteke B, Nkengasong JN, Kestens L (2011) Low CD4+ T cell counts among African HIV1 infected subjects with group B KIR haplotypes in the absence of specific inhibitory KIR ligands. PLoS One 6, e17043

Jennes W, Verheyden S, Mertens JW, Camara M, Seydi M, Dieye TN, Mboup S, Demanet C, Kestens L (2013) Inhibitory KIR/HLA incompatibility between sexual partners confers protection against HIV-1 transmission. Blood 121:1157-1164

Jiang W, Johnson C, Jayaraman J, Simecek N, Noble J, Moffatt MF, Cookson WO, Trowsdale J, Traherne JA (2012) Copy number variation leads to considerable diversity for B but not A haplotypes of the human KIR genes encoding NK cell receptors. Genome Res 22: $1845-1854$

Jiang Y, Chen O, Cui C, Zhao B, Han X, Zhang Z, Liu J, Xu J, Hu Q, Liao $\mathrm{C}$ et al (2013) KIR3DS1/L1 and HLA-Bw4-80I are associated with HIV disease progression among HIV typical progressors and longterm nonprogressors. BMC Infect Dis 13:405

Kaslow RA, Dorak T, Tang JJ (2005) Influence of host genetic variation on susceptibility to HIV type 1 infection. J Infect Dis 191:S68-S77

Kuśnierczyk P, Mozer-Lisewska I, Zwolińska K, Kowala-Piaskowska AE, Bura M, Bereszyńska I, Pauli A, Żeromski J (2015) Contribution of genes for killer cell immunoglobulin-like receptors (KIR) to the susceptibility to chronic hepatitis $\mathrm{C}$ virus infection and to viremia. Hum Immunol 76:102-108

Lama J, Planelles V (2007) Host factors influencing susceptibility to HIV infection and AIDS progression. Retrovirology 4:52

Lanier LL (1998) NK cell receptors. Annu Rev Immunol 16:359-393

Long EO, Rajagopalan S (2000) HLA class I recognition by killer cell Iglike receptors. Semin Immunol 12:101-108

Mabuka JM, Mackelprang RD, Lohman-Payne B, Majiwa M, Bosire R, John-Stewart G, Rowland-Jones S, Overbaugh J, Farquhar C (2009) CCR2-64I polymorphism is associated with lower maternal HIV-1 viral load and reduced vertical HIV-1 transmission. J Acquir Immune Defic Syndr 51:235-237

Mahajan SD, Agosto-Mojica A, Aalinkeel R, Reynolds JL, Nair BB, Sykes DE, Martinez J, Adams J, Singh N, Bernstein Z et al (2010) Role of chemokine and cytokine polymorphisms in the progression of HIV-1 disease. Biochem Biophys Res Commun 396:348-352

Martin MP, Carrington M (2013) Immunogenetics of HIV disease. Immunol Rev 254:245-264

Martin AM, Freitas EM, Witt CS, Christiansen FT (2000) The genomic organization and evolution of the natural killer immunoglobulin-like receptor (KIR) gene cluster. Immunogenetics 51:268-280

Martin MP, Gao X, Lee J-H, Nelson GW, Detels R, Goedert JJ, Buchbinder S, Hoots K, Vlahov D, Trowsdale J et al (2002) Epistatic interaction between KIR3DS1 and HLA-B delays the progression to AIDS. Nat Genet 31:429-434

Martin AM, Kulski JK, Gaudieri S, Witt CS, Freitas EM, Trowsdale J, Christiansen FT (2004) Comparative genomic analysis, diversity and evolution of two KIR haplotypes A and B. Gene 335:121-131

Martin MP, Qi Y, Gao X, Yamada E, Martin JN, Pereyra F, Colombo S, Brown EE, Shupert WL, Phair J et al (2007) Innate partnership of HLA-B and KIR3DL1 subtypes against HIV-1. Nat Genet 39:733740

Merino A, Malhotra R, Morton M, Mulenga J, Allen S, Hunter E, Tang J, Kaslow RA (2011) Impact of a functional KIR2DS4 allele on 
heterosexual HIV-1 transmission among discordant Zambian couples. J Infect Dis 203:487-495

Mozer-Lisewska I, Zwolińska K, Kowala-Piaskowska AE, Bura M, Rozpłochowski B, Pauli A, Zeromski J, Piasecki E, Kuśnierczyk P (2015) Genetic (KIR, HLA-C) and some clinical parameters influencing the level of liver enzymes and early virologic response in patients with chronic hepatitis C. Arch Immunol Ther Exp 64:65-73

Niepiekło-Miniewska W, Zuk N, Dubis J, Kurpisz M, Senitzer D, Havrylyuk A, Grendziak R, Witkiewicz W, Chopyak V, Kuśnierczyk P (2014) Two new cases of KIR3DP1, KIR2DL4negative genotypes, one of which is also lacking KIR3DL2. Arch Immunol Ther Exp 62:423-429

O'Brien SJ, Moore JP (2000) The effect of genetic variation in chemokines and their receptors on HIV transmission and progression to AIDS. Immunol Rev 177:99-111

O’Connell KA, Han Y, Williams TM, Siliciano RF, Blankson JN (2009) Role of natural killer cells in a cohort of elite suppressors: low frequency of the protective KIR3DS1 allele and limited inhibition of human immunodeficiency virus type 1 replication in vitro. J Virol 83:5028-5034

O'Connor GM, Vivian JP, Gostick E, Pymm P, Lafont BAP, Price DA, Rossjohn J, Brooks AG, McVicar DW (2015) Peptide-dependent recognition of HLA-B*57:01 by KIR3DS1. J Virol 89:5213-5221

Paximadis M, Minevich G, Winchester R, Schramm DB, Gray GE, Sherman GG, Coovadia AH, Kuhn L, Tiemessen CT (2011) KIRHLA and maternal-infant HIV-1 transmission in Sub-Saharan Africa. PLoS ONE 6, e16541

Reynoso R, Laufer N, Hackl M, Skalicky S, Monteforte R, Turk G, Carobene M, Quarleri J, Cahn P, Werner R et al (2014) MicroRNAs differentially present in the plasma of HIV elite controllers reduce HIV infection in vitro. Sci Rep 4:5915

Robinson J, Halliwell JA, McWilliam H, Lopez R, Marsh SGE (2013) IPD-the immuno polymorphism database. Nucleic Acids Res 41: D1234-D1240

Takeshita LYC, Gonzalez-Galarza FF, dos Santos EJM, Maia MHT, Rahman MM, Zain SMS, Middleton D, Jones AR (2013) A database for curating the associations between killer cell immunoglobulin-like receptors and diseases in worldwide populations. Database J Biol Databases Curation 2013, bat021

Tallon BJM, Bruneau J, Tsoukas CM, Routy J-P, Kiani Z, Tan X, Bernard NF (2014) Time to seroconversion in HIV-exposed subjects carrying protective versus non protective KIR3DS1/L1 and HLA-B genotypes. PLoS One 9, e110480
Tan X, Zhang J, Di C, Hu A, Yang L, Qu S, Zhao R, Yang P, Guo S (2010) Distribution of CCR5-Delta32, CCR5m303A, CCR2-64I and SDF1-3'A in HIV-1 infected and uninfected high-risk Uighurs in Xinjiang, China. Infect Genet Evol 10:268-272

Tiemessen CT, Paximadis M, Minevich G, Winchester R, Shalekoff S, Gray GE, Sherman GG, Coovadia AH, Kuhn L (2011) Natural killer cell responses to HIV-1 peptides are associated with more activating KIR genes and HLA-C genes of the C1 allotype. J Acquir Immune Defic Syndr 57:181-189

van der Kuyl AC (2012) HIV infection and HERV expression: a review. Retrovirology 9:6

Vieira VC, Barral MFM, Mendoza-Sassi RA, Silveira JM, Soares MA, de Martínez AMB (2011) The effect of combined polymorphisms in chemokines and chemokine receptors on the clinical course of HIV1 infection in a Brazilian population. Mem Inst Oswaldo Cruz 106: 408-415

Wilson MJ, Torkar M, Haude A, Milne S, Jones T, Sheer D, Beck S, Trowsdale J (2000) Plasticity in the organization and sequences of human KIR/ILT gene families. Proc Natl Acad Sci 97:4778-4783

Xu L, Qiao Y, Zhang X, Sun H, Wang J, Sun D, Jin Y, Yu Y, Chen F, Bai J et al (2010) CCR2-64I allele is associated with the progression of AIDS in a Han Chinese population. Mol Biol Rep 37:311-316

Zapata W, Aguilar-Jiménez W, Pineda-Trujillo N, Rojas W, Estrada H, Rugeles MT (2013) Influence of CCR5 and CCR2 genetic variants in the resistance/susceptibility to HIV in serodiscordant couples from Colombia. AIDS Res Hum Retrovir 29:1594-1603

Zwolińska K (2006) Retroviruses-derived sequences in the human genome. Human endogenous retroviruses (HERVs). Postepy Hig Med Dosw 60:637-652

Zwolińska K (2009) Host genetic factors associated with susceptibility to HIV infection and progression of infection. Postepy Hig Med Dosw 63:73-91

Zwolińska K, Knysz B, Gąsiorowski J, Pazgan-Simon M, Gładysz A, Sobczyński M, Piasecki E (2013a) Frequency of human endogenous retroviral sequences (HERV) K113 and K115 in the Polish population, and their effect on HIV infection. PLoS One 8, e77820

Zwolińska K, Knysz B, Rybka K, Pazgan-Simon M, Gąsiorowski J, Sobczyński M, Gładysz A, Piasecki E (2013b) Protective effect of CCR5- $\Delta 32$ against HIV infection by the heterosexual mode of transmission in a Polish population. AIDS Res Hum Retrovir 29: $54-60$ 